\title{
O TEMPO NA TRAJETÓRIA DAS FAMÍLIAS QUE BUSCAM A JUSTIÇA ${ }^{\star}$
}

\author{
Marcia Regina Ribeiro dos Santos \\ Liana Fortunato Costa ${ }^{\star}$
}

\begin{abstract}
Resumo
Estudar o tempo em sua multiplicidade de entendimentos é importante para os profissionais psicossociais na medida em que a experiência de atuação com familias em litígio e que buscam a justiça exige celeridade. Como conciliar os diferentes tempos do indivíduo, da família, da lei, do juiz, do profissional nas decisões sobre a família? A sociedade exige que a Justiça seja feita de forma mais rápida, mas os prazos estabelecidos em lei nem sempre são compativeis com o tempo "exigido" pelo indivíduo ou pela sociedade. Por outro lado os prazos processuais têm a função de proteger a sociedade em seus anseios.
\end{abstract}

Palavras-chave: Tempo. Família. Psicologia juridical. Avaliação psicossocial.

\section{TIME SPENT BY FAMILIES IN SEARCH FOR JUSTICE}

\begin{abstract}
To study time, in its multiplicity of understanding, is important for psychosocial professionals inasmuch as the experience of dealing with families who are in dispute and search for Justice demand celerity. How to reconcile the different times of the individual, the family, the law, the judge and the professional in the decisions about the family? Society demands that Justice is made in the fastest way but the terms stablished by law are not always compatible with the term "required" by the individual or the society. On the other hand, the process terms have to protect the society in its spectations.
\end{abstract}

Keywords: Time. Family. Forensic psychology. Psychosocial evaluation.

\footnotetext{
* Este trabalho foi apresentado no VI Congresso Brasileiro de Terapia Familiar, em Florianópolis, Santa Catarina, em julho de 2004.

$\star \star$ Psicóloga Jurídica, Terapeuta Familiar, Gestalterapeuta. Psicóloga do Serviço Psicossocial Forense-Seção Psicossocial Forense Centro do Tribunal de Justiça do Distrito Federal e Territórios SQSW 101 Bloco J ap. 404 - Setor Sudoeste Brasília - DF-70.670 110 Tel: 6133443991 Fax: 6133437876

E-mail: marciarrsantos@uol.com.br

$\star \star \star$ Psicóloga, Terapeuta Familiar, Psicodramatista. Doutora em Psicologia Clínica pela Universi dade de São Paulo, Docente Permanente da Universidade de Brasília SQN 104 Bloco D ap. 307 Brasília - DF - 70.733040 Tel: 6133287439 Fax: 6133269710

E-mail: lianaf@terra.com.br
} 
Marcia Regina Ribeiro dos Santos e Liana Fortunato Costa

El conocimiento del tiempo es, por tanto, múltiple. Cada concepción tiene su tiempo.

(BOSCOLO; BERTRANDO, 1996, p.38)

\section{INTRODUÇÃo}

O objetivo do presente artigo é refletir acerca das diferenças entre as concepções sobre o tempo dos pontos de vista jurídico e psicológico, nos casos de decisões judiciais que envolvem famílias em litígio. Neste sentido, há que se considerar: a) o juiz, principal protagonista do processo (TUCCI, 1997), como o sujeito que deve atuar para emitir a sentença, com um tempo exíguo, e de forma neutra em suas decisões; b) as famílias, que estão em conflito há muito tempo e que buscam ajuda da Justiça por meio dos processos; e c) os profissionais - psicólogos, assistentes sociais e pedagogos - que atuam na Justiça emitindo pareceres técnicos (avaliação psicossocial) com o intuito de subsidiar os magistrados em suas decisões, e que devem fazê-lo o mais breve possível.

Buscamos realizar tais reflexões pelo fato de o contexto jurídico estar vivenciando um dilema em função das diferentes formas de se considerar o tempo nesse contexto: o tempo e as famílias que buscam a Justiça; o tempo e os juízes; o tempo e os profissionais de uma Seção Psicossocial Forense. Esse dilema se dá na medida em que o processo, que tramita nas Varas de Família e que trata de guarda, tutela, regulamentação de visita, e até mesmo os de Vara Criminal, está sob a égide de paradigmas teóricos diferentes, ao longo de seu percurso. A Psicologia busca conhecer a dinâmica familiar com um paradigma compreensivo e o Direito aplica seu paradigma normativo ao regular também questões familiares. Costa, Penso e Almeida (2005) já publicaram suas reflexões sobre a aproximação e o reconhecimento dos limites e possibilidades da interdisciplinaridade Psicologia/Direito, especialmente na área de abuso sexual infantil, enfatizando que o trabalho conjunto dos profissionais dessas áreas é decisivo no sentido reparador da proteção à criança violentada. Se a Psicologia favorece a construção da significação da violência, o Direito favorece a dimensão decisória tão necessária nas intervenções nesta área de atuação.

Nossa opção teórica para pensar e atuar com famílias é a perspectiva sistêmica (ANDOLFI; ÂNGELO, 1989; BOSCOLO; BERTRANDO, 1996; VASCONCELLOS, 2002), quando enfatizamos que o tempo de elaboração dos jogos relacionais presentes na família, além de variar de família para família, é vivido de forma tanto mítica quanto atualizada. O tempo, na experiência da relação familiar, é vivido como um processo de aproximações e separações incluindo vivências simultâneas, que envolvem gerações diferentes, que se encontram em "tempos" diferentes.

Por outro lado, pensamos no tempo em relação aos procedimentos judiciais, na perspectiva proposta por Araújo Pinto (2002), que resgata as contribuições da física quântica para esse tema e sua discussão no contexto de decisões, que é a característica do sistema judiciário. 


\section{SOBRE O TEMPO}

O tempo, para o mundo ocidental, sempre foi considerado importante para ser estudado. No entendimento dos gregos, o mundo era imutável e eterno, sendo o planeta Terra considerado o centro do universo, e os outros planetas giravam em torno dele. Platão, em seus estudos, associou o tempo ao universo, ou seja, aos movimentos dos corpos celestes. Aristóteles, por sua vez, ampliou esse pensamento e associou o tempo ao movimento. Ele o definia como o número do movimento segundo o antes e o depois. Assim, Aristóteles reconheceu a realidade do tempo, sem abandonar a relação com o Ser (ARAÚJO PINTO, 2002).

Para Bergé, Pomeau e Dubois-Gange (1996) o ser humano sempre esteve preocupado com o tempo, tanto do ponto de vista da vida interior como exterior, numa tentativa de controlar a imprevisibilidade dos acontecimentos, diante de sua imensa angústia em relação ao desconhecido. Embora este interesse tenha se mostrado desde a Antiguidade, ele vem se fixando em pontos diversos que revelam a própria história da humanidade: a Bíblia, as predições, a Astronomia, a Matemática, até a Física, em especial a Física Quântica.

É necessário que façamos algumas considerações sobre conceitos básicos a respeito do tempo, antes da elaboração de comentários mais específicos sobre a relação da Justiça com a família no que concerne ao uso ou demanda de tempo. Aion é o tempo do sempre, sem limites, a eternidade. Cronos é o tempo mensurável e Kairos é o tempo dotado de significado (BOSCOLO; BERTRANDO, 1996). Para o nosso propósito é importante considerar principalmente Cronos e Kairos, visto que as famílias consideram todo o tempo "gasto" com o processo judicial como um tempo de sofrimento ("Período terrível para nós!"). Mas também se pode argumentar com a possibilidade de que este tempo seja "gasto" em um processo de significação e ressignificação da relação familiar, como propõem Costa e Santos (2004b).

Ainda segundo Boscolo e Bertrando (1996), outro aspecto a ser apontado é a constatação de que a História contém um tempo linear e um tempo cíclico. O tempo linear é uma contagem numérica de um período, o tempo cíclico é a percepção significadora do período, ou seja, a percepção histórica dos eventos. Todos os atores do Judiciário têm queixas sobre o período de tramitação de um processo. Em nossa experiência, vimos processo de criança abusada sexualmente que teve sua sentença final cinco anos após seu início. Também está presente no processo o tempo cíclico da família, com suas repetições de conflitos geração após geração. Sob o ângulo do processo em si, o que conta é o tempo linear, porém para as mudanças familiares o que conta é o tempo da construção da significação histórica da interação familiar. Neste sentido, a relação da família com o Judiciário pode representar uma oportunidade de outra valorização para antigos conflitos, na medida em que o contato com o juiz possa oferecer uma outra dimensão do tempo histórico.

Não é nossa intenção discorrer ou discutir sobre conceitos da Física Clássica e/ou da Física Quântica. Apenas achamos fundamental apontar alguns avanços e questionamentos decorrentes das novas teorias surgidas no século passado e que nos trouxeram novas formas de pensar sobre o tempo. 
Em livro que reúne uma série de entrevistas com expoentes do pensamento da atualidade, Pessis-Pasternak (1993) procura simplificar conceitos extremamente complexos. A entrevista com Ilya Prigogine, químico, criador da teoria das "estruturas dissipativas", nos mostra que esta teoria explica a ordem pela desordem, e devolve o ser humano a uma condição de parte integrante do Universo, como observador e observado. Prigogine também propôs o conceito de "ordem por flutuações" que mostra que o caos entrópico, através de flutuações/bifurcações, é fonte de evolução e do surgimento de novas organizações complexas. Este enfoque científico aponta para a importância do tempo irreversível, como um "fluxo do devir" e aspecto fundamental de toda "mudança". Os avanços científicos se encontram sob o questionamento dos fenômenos do "devir, da reabilitação da desordem e do acaso organizador". As crenças das ciências contemporâneas se voltam para as instabilidades, as flutuações e as bifurcações apontando para a existência de um "paradoxo do tempo", pois vivemos o tempo, hoje, como irreversível. Algumas imagens como a flecha do tempo e o experimento do pêndulo, que poderiam contrariar a irreversibilidade do tempo, tendem na direção da assertiva " $O$ tempo é uma ilusão", existente desde a Física Clássica.

Outro aspecto na obra de Prigogine diz respeito à retomada das experiências de Boltzman sobre a irreversibilidade do tempo, que ainda se constitui no paradoxo do tempo, também chamado paradoxo da irreversibilidade. Para esse químico, o núcleo do paradoxo está em toda parte, sendo que o passado e o futuro desempenham papéis diferentes (ARAÚJO PINTO, 2002).

Um outro fator importante e de interesse de todos é a questão da contagem do tempo, de sua periodicidade como trata a Física (BERGÉ; POMEAU; DUBOISGANGE, 1996). Mais do que a contagem do tempo (o tic-tac do relógio), é a sensação (pessoal e diferenciada) da duração do tempo. Os estudos sobre o movimento dos pêndulos trouxeram conhecimento sobre harmonia, periodicidade, sincronização, em especial a sincronização de ritmos. O "mecanismo" da sincronização pode acontecer envolvendo seres vivos em ações intencionais ou não. Para nosso interesse em demonstrar que estes construtos teóricos estão ligados aos impasses presentes na condução do processo judicial, considerando juízes e famílias, é importante dizer que “tão logo a 'estimulação' de sincronização desaparece, uma certa desorganização pode aparecer com a ressurgência de cada individualidade" (BERGÉ; POMEAU; DUBOIS-GANGE, 1996, p. 122).

Nós todos estamos submetidos a um número imenso de ritmos que são internos e que também nos chegam do meio ambiente. Este conjunto é complexo, quando se pensa em interação de sistemas diferentes. No caso dos processos judiciais, a interação envolve o ritmo do sistema judicial (lento e burocrático) e o do sistema familiar (sofrido e urgente). Por outro lado, é também fundamental se compreender melhor a existência de comportamentos caóticos deterministas. Estes comportamentos caóticos são uma propriedade intrínseca dos seres vivos. Os dois tipos de comportamentos, rítmico e caótico, estão associados e presentes na vida e ocasionam intervenções não lineares nos acontecimentos (BERGÉ; POMEAU; DUBOIS-GANGE, 1996). Um processo de mudança de guarda, durante o qual se descobre que uma criança sofre abuso sexual por parte de um dos 
genitores, é exemplo de situação que envolve uma tomada de decisões considerando os dois comportamentos.

O que podemos depreender, de forma simplificada e acessível ao não estudioso das ciências matemáticas, é que o tempo é perceptível na experiência da matéria, pois, conforme Stephen Hawkins nos diz em seu livro Uma Breve História do Tempo, espaço e tempo têm diferenças acidentais (decorrentes do movimento do big-bang) e desta forma não podemos ter uma percepção simultânea da vida; temos percepções fragmentadas e assim o tempo se impõe (PESSISPASTERNAK, 1993).

O tempo de duração excessiva de um processo, aspecto que preocupa juristas na atualidade, "provoca erosão das provas, demora na justa reparação do direito violado, a agravação do custo econômico do sistema, e das partes constituindo um desincentivo ao recurso ao tribunal" (SANTOS et al., 1996, p. 387). Há aí um aspecto paradoxal que deve ser observado. Por um lado a celeridade do processo significa um direito fundamental do cidadão à Justiça, porém, de outra forma, esta celeridade não pode pôr em risco a segurança de proteção dos direitos do cidadão. Por isso, o debate que se instala no meio civil e jurídico, sobre a questão do tempo do processo judicial, torna-se tão oportuno e importante, agregando dimensões de diferentes disciplinas. Buscamos discutir o tempo, considerando suas implicações nesse contexto justiça/família/profissional psicossocial, de modo a ressaltar o papel estratégico que o tempo tem na consolidação da democracia na sociedade contemporânea (SANTOS et al., 1996).

\section{O TEMPO NA FAMÍLIA}

Ao longo da história de construção e reconstrução dos conceitos que nortearam a Terapia Familiar Sistêmica, chegamos ao quadro atual de influências dos novos paradigmas da ciência contemporânea, que tem como expoentes, no Brasil, os trabalhos teóricos de Maria José Esteves de Vasconcellos (1995, 1996, 2002) e Marilene Grandesso (2000, 2002). Esta mudança paradigmática parte de aquisições vindas de outras ciências como a Física, a Cibernética, a Filosofia, a Lingüística, a Hermenêutica e a Sociologia. De forma geral, se questionam conceitos dominantes como a simplicidade, a estabilidade e a objetividade que orientavam as intervenções terapêuticas na década de 1960, época do surgimento sistematizado dos estudos sistêmicos sobre família. As abordagens familiares que assimilaram estas mudanças caminham no sentido da narratividade, da auto-reflexão, do diálogo e da contextualização. No bojo destas influências, a questão do tempo tem tido maior atenção; passou-se a dar maior destaque ao ato da significação e da interpretação do campo da intersubjetividade. O processo da significação e interpretação tem parâmetros diferenciados, não generalizáveis para sua expressão. Em termos práticos saímos dos prazos exíguos de entrar em contato com a família, para os prazos necessários (mais longos) para que a família construa sua significação sobre a experiência da convivência, privilegiando a possibilidades das mudanças ocorrerem no espaço de conversação familiar. E como fica a marcação de audiências no sistema judicial diante desta nova realidade? Como se pode cum- 
prir prazos ou seguir agendas quando as famílias reagem diferentemente a partir de encontros com juízes e/ou psicólogos e assistentes sociais? Como argumentar com os operadores do Direito que a família necessita de um "tempo" para estabelecer uma conversação que seja transformadora?

Boscolo e Bertrando, terapeutas de família, buscaram aprofundar o conhecimento em torno do tempo quando começaram a perceber, durante o trabalho que realizavam junto às famílias, "a importância da relação entre o tempo e a modificação das expectativas em clientes e terapeutas" (BOSCOLO; BERTRANDO, 1996, p. 11). Embora esses terapeutas tenham ampliado o conhecimento que tinham até então, através da perspectiva do tempo, verificaram que as diferentes concepções de tempo adotadas pelos físicos têm certa analogia com os tempos vividos pela pessoa comum. Segundo estes autores, no determinismo clássico, os acontecimentos estão ordenados de modo causal, em um único tempo, comum a todos. Assim, o passado determina o presente que determina o futuro. Para esses terapeutas, o conhecimento dos diferentes modos de entender o tempo "é útil para enriquecer não somente a cultura, mas também a capacidade de atuar movendo-se com destreza nas diferentes concepções" (BOSCOLO; BERTRANDO, 1996, p. 38). Afirmam ainda que "o conhecimento do tempo é, portanto, múltiplo. Cada concepção tem seu tempo" (BOSCOLO; BERTRANDO, 1996, p. 38).

Considerando os relacionamentos humanos e familiares, há diferenças entre o sentido de tempo objetivo e o sentido de tempo subjetivo individual - passado, presente e futuro. Nos relacionamentos interpessoais, os tempos individuais são compartilhados, levando-se em conta os contextos culturais e sociais em que estão inseridos (BOSCOLO; BERTRANDO, 1996). Tanto o tempo de um processo judicial como o tempo de um julgamento evidenciam esta observação de um tempo compartilhado, porém com nuances diferentes de significação. Gostaríamos de exemplificar uma situação, que vivemos como observadoras, que coloca em foco estes descompassos presentes nos tempos compartilhados: a audiência final de um processo de denúncia de abuso sexual de uma menina de 12 estava em andamento. Durante a avaliação psicossocial realizada por uma psicóloga do Tribunal, da Seção Psicossocial Forense, ficou evidente que a menina reconhecia o pai como o abusador. Durante a audiência em questão, que contava também com a presença do pai, a menina recusou-se a confirmar para o juiz este reconhecimento. A psicóloga estava presente na audiência e pediu ao juiz para interromper os trabalhos e dar a todos um tempo de recomposição das emoções e conseqüente sofrimento. Considerando que este processo pode ter demorado dois/quatro anos para chegar à sentença final, como se sente um juiz ao adiar mais uma vez, mesmo que por um tempo pequeno, a possibilidade de finalização do trabalho? Como pode este juiz perceber a importância de uma intervenção potente e significadora, junto à menina, em momento tão urgente?

O ápice da conexão tempo e família se dá no conceito de Transmissão Geracional de Murray Bowen, que foi um teórico e terapeuta familiar (era psiquiatra de formação psicanalítica), um dos iniciadores da Terapia Familiar Sistêmica e que contribuiu com a construção de vários conceitos como triangulação, diferenciação do eu, massa de ego familiar indiferenciada, projeção familiar. Porém o 
conceito que mais está ligado ao que queremos aqui discutir é o de Transmissão Geracional que se constitui num processo de projeção familiar, que se repete de geração a geração, durante longos períodos de tempo, e que leva a um maior ou menor grau de diferenciação de seus membros. Este grau de diferenciação possibilita a construção de individualidades e está ligado ao potencial de saúde da família (PAPERO, 1998). A influência dos conceitos bowenianos sobre a Terapia Familiar tem sido imensa, e no contexto judicial sempre está presente esta dimensão que volta sua atenção para a importância da observação no processo temporal. Se a promulgação da sentença é realizada com base na lei, a confecção do relatório psicossocial é feita com base na observação que exige tempo, e no levantamento da história transgeracional de cada família.

Um outro teórico da Terapia Familiar, Ivan Boszornenyi-Nagy, contribuiu com o conceito de construção das lealdades invisiveis, que se coloca juntamente ao conceito acima citado como formador das fronteiras entre gerações e entre membros de uma mesma geração. As situações de violência, e em especial de violência sexual infantil intrafamiliar, apontam para o papel do tempo na destruição progressiva destas fronteiras e também na reconstrução gradual de novas fronteiras (BOSZORMENYI-NAGY; SPARK, 1983).

A ciência política, mais que nunca, volta-se para um intrigante aspecto da realidade que diz respeito ao crescente protagonismo social e político dos tribunais na vida dos cidadãos comuns (SANTOS et al., 1996). Neste momento, muitas famílias buscam a ajuda da Justiça para definição da partilha de bens, da pensão alimentícia, da guarda ou da visitação dos filhos. Muitas vezes, a família pode vivenciar as decisões judiciais como ordens de cunho destrutivo, mesmo que o todo, o grupo familiar, tenha interesse na solução do caso, e necessite muito tempo até que a elaboração emocional da sentença ocorra. É importante lembrar que os subsistemas conjugal e filial têm interesses diferentes, dependendo da idade cronológica e da maturidade emocional. Do ponto de vista emocional, cada um terá seu tempo para elaborar uma nova forma de estar no mundo, existindo mais uma vez, diferentes tempos - cronológico, legal e, principalmente emocional - para que tal aconteça.

\section{O TEMPO NA JUSTIÇA}

Neste item gostaríamos de iniciar apontando uma análise sociológica, bastante atual, realizada por Santos, B. S. (1996), que discute sua perspectiva dos processos de estruturação social e as constelações de relações sociais que levam, ou não, aos processos de transformação social. Nesta análise, o autor considera quatro constelações de relações sociais: o espaço-tempo doméstico, o espaço-tempo da produção, o espaço-tempo da cidadania e o espaço-tempo mundial. Nossa preocupação com os diferentes sentidos que o tempo tem para os dois sistemas que estamos discutindo, nos leva a chamar a atenção para as questões contidas no espaço-tempo da cidadania. Este construto é descrito como: "constituído pelas relações entre o Estado e os cidadãos, e nele se gera uma forma de poder, a dominação, que estabelece a desigualdade entre cidadãos e Estado [...]" (SANTOS, 
1996, p. 314). O espaço-tempo da cidadania compreende ainda dimensões outras como comunidade, relações de vizinhança, aspectos de etnia e religião, que envolvem relações de igualdade/desigualdade. O poder judiciário está atento a estas transformações, um exemplo é a criação de uma ação recente e ainda em implantação, que é a Justiça Comunitária (PROJETO Justiça Comunitária, 2001). O que queremos discutir aqui é a diferença de poder, ainda profunda, existente entre o cidadão comum (no nosso caso a família) e a Justiça. Uma sentença judicial define, reestrutura, modifica, transforma, altera, empobrece, enriquece as relações familiares, promovendo um marco definidor de rupturas/uniões no tempo da convivência familiar. O que está em jogo, mais que nunca, é a questão dos Direitos Humanos, e da necessidade urgente da Justiça retomar a referência da humanidade para seu balizamento (DELMAS-MARTY, 2001).

Sobre o Direito é importante apontar sua normatização que se constituiu desde as sociedades antigas, à medida que as mesmas foram se tornando mais complexas. Posteriormente, passou-se à necessidade de existir os processos decisórios, surgindo, então, o Direito institucional. A partir desse momento, a decisão deve ser tomada em situações em aberto e o direito passa a absorver a incerteza, por meio de complexos sistemas processuais. Além disso, torna-se necessária a neutralidade do juiz (ARAÚJO PINTO, 2002). Este autor ressalta que:

a dimensão do sentido do direito envolve, agora, a moralidade das partes envolvidas nas disputas jurídicas. Apresenta-se, neste contexto, uma dicotomia lógica para o juiz: apenas uma das partes tem razão. As partes se submetem, então, por meio dos procedimentos decisórios, à concepção normativa e material exteriorizada pelo juiz: trata-se aqui de uma moral (ou razão) pretensamente genérica. (ARAÚJO PINTO, 2002, p. 225)

De acordo ainda com Araújo Pinto (2002), com a complexidade das sociedades, surge a necessidade de se estabelecer as contraposições de uma decisão, decorrendo daí as concepções de justo e correto. A lei existe para que a ordem se faça presente e o juiz é a pessoa constituída por autoridade pública para administrar justiça (PAULO; ALEXANDRINO, 2002). A lei tem sua vigência por tempo determinado, quando o prazo final está previamente estabelecido, ou por tempo indeterminado, enquanto não for modificada, por decretos, emendas, dentre outras. A mudança de uma lei pode ocorrer por iniciativa da sociedade, dos parlamentares, ou do governo. As mudanças ocorridas por iniciativa da sociedade são construídas no decurso de um tempo no qual novos valores culturais vão se agregando aos antigos. Quando tais mudanças culturais se efetivam e a alteração da lei não acompanha essas mudanças, há uma pressão da sociedade para a legalização da situação fática. Há mudanças que acontecem em maior ou menor tempo, pois dependem do tempo que a sociedade levou para incorporar a mudança, assim como vai depender de como os parlamentares incorporarão a necessidade da mudança.

No evento "A Nova Justiça: desafios e tendências", ocorrido em Brasília, em agosto de 2006, vários juristas (ministro Carlos Ayres Britto do Superior Tribunal Federal, promotoras de justiça Selma Leite do Nascimento e Luisa de Marillac Pantoja e promotor de justiça Anderson Pereira de Andrade) e profissi- 
onais psicossociais (psicólogas Helenice Gama Dias de Lima e Sônia Maria Virgílio Veiga) enfatizaram a urgência em se considerar a questão da subjetividade dos atores do Judiciário nos vários momentos e aspectos do processo judicial. Em especial, os palestrantes falaram sobre a figura do juiz, chamando a atenção para dois pontos em particular: a pouca idade que muitos juízes apresentam no exercício da função, em virtude de prestarem concurso para o cargo logo que terminam a graduação e a grande angústia que os leva a vivenciarem a tomada de decisões que é feita sob sua única responsabilidade. Este fórum representa uma preocupação de algumas Corregedorias de Tribunais que se voltam para o questionamento da subjetividade dos atores judiciais que participam do momento dos julgamentos. Julga com maior competência aquele juiz que está há muitos anos no exercício da função? Ou efetua melhor análise das circunstâncias aquele juiz que mesmo sem tanta experiência, tem uma formação mais recente e provavelmente mais atualizada? As autoras, profissionais que vêm lidando diariamente com esta realidade da interdisciplinaridade Direito/ Psicologia, não têm uma resposta pronta para estas questões, pois têm entrado em contato com juízes com pouco tempo de prática e que têm bom senso e sensibilidade para lidarem com os conflitos e o sofrimento da família. Mas também têm visto juízes com bastante prática que não conseguem lidar com as famílias numa perspectiva interacional, privilegiando as informações do processo acima dos interesses do grupo familiar como um todo.

Cabe ainda comentar sobre novos procedimentos que a Justiça vem adotando para dar maior celeridade às decisões judiciais. Oliveira (2004) indica a preocupação que o judiciário tem com as questões de tempos e prazos, através da criação de um instrumento de solução extrajudicial de conflitos e aponta como relevantes: a Lei 9307 que deu novo tratamento jurídico à arbitragem, a Lei 9958 que instituiu a Conciliação Prévia e a Lei 9099 que dispôs sobre Juizados Cíveis e Criminais. Estes Juizados Especiais têm como objetivo o atendimento imediato dos conflitos e visam restabelecer a comunicação e os direitos, facilitando o acesso de vítimas à justiça, conforme postula Romão (2001).

Uma tendência, cada vez mais experimentada em tribunais é a mediação, na tentativa de aceleração de prazos. A mediação é um procedimento que surge na esteira das novas práticas advindas de novas perspectivas sobre a ciência. A mediação busca facilitar o diálogo entre as partes e promover o entendimento célere sobre situações conflitivas (SCHNITMAN, 1999). Nossa cultura sempre privilegiou o paradigma ganhar-perder e a prática dos julgamentos sempre se pautou por este parâmetro. A mediação busca a resolução de conflitos através da dimensão da reflexividade entre as partes litigantes.

Embora a mediação não tenha uma regulamentação em lei, carrega, em si, grandes expectativas dos operadores do Direito e da Psicologia. Schnitman (1999, p. 25) enfatiza o caráter inovador da mediação, pois "não se trata, assim, de uma atividade técnica, mas da ativa construção de marcos de interpretação, que envolvem valores e pontos de vista". 


\section{O TEMPO E OS PROFISSIONAIS PSICOSSOCIAIS DA JUSTIÇA}

No caso dos processos encaminhados a uma Seção Psicossocial Forense, há que se considerar o tempo que o mesmo ficará na referida Seção. Assim, dependerá da interpretação do juiz, no que se refere aos prazos e a sua percepção do sofrimento da família, a pressão que esta, ou um de seus membros ou seu representante legal puder exercer sobre ele, a fim de decidir de forma favorável ao seu pedido. O juiz de Vara de Família tem conhecimento, tanto dos fatos relacionados à família, por meio dos autos que estão em suas mãos, quanto das leis que irão respaldálo em suas decisões. Para que tal aconteça, este juiz deverá se manter o mais isento possível durante a tomada de decisões. Os autos deverão conter todos os elementos necessários para que a decisão se concretize.

As condições de relações estabelecidas entre os profissionais psicossociais, durante a realização da avaliação psicossocial, encontram diferenças marcantes com as condições de relação, descrita acima, estabelecida entre o juiz, o processo e a família. Estes profissionais, que assessoram o juiz em suas decisões, entram em contato com outras significações dadas pelas famílias aos conflitos, que muitas vezes são paradoxais em relação a significações apreendidas pelo juiz nas oitivas. Um processo, mais completo de significação, envolve um tempo diverso daquele dos processos judiciais, na medida em que se dá no vagaroso processo de elaboração psíquica e emocional de vivências habitualmente tão sofridas e traumáticas. Em relação às famílias, se dá no processo imprevisível de significação e ressignificação presente nas conversações ocorridas entre as famílias e os atores do Judiciário, e entre os membros da família (COSTA; SANTOS, 2004a, 2004b; GRANDESSO, 2000).

Tomando-se como exemplo as denúncias de abuso sexual intrafamiliar, somente em um longo processo terapêutico, iniciado após a denúncia pública, e com um maior distanciamento deste fato, as pessoas nele implicadas se permitem entrar em contato com lembranças desconhecidas conscientemente e, por conseguinte, atribuir significados pela primeira vez ou significados novos ao ato em si. Em contraposição, a avaliação psicossocial requerida pelos juízes, nos casos de abuso, nem sempre mostra significações mais profundas associadas às reações tanto da criança como da família. Um dos empecilhos à realização dessas associações se deve ao curto tempo da referida avaliação investigatória, que impossibilita a vinculação afetiva entre os envolvidos na denúncia e a equipe do psicossocial. No caso dos juízes, há um agravante que se trata da enorme distância social e institucional que o papel de juizado tem em relação ao cidadão comum que busca seus direitos. A confiança e o compartilhar dos segredos íntimos com os profissionais exigem um tempo próprio da família e das crianças, além da própria construção de uma malha mais profunda de significados para os atos cometidos.

Temos trabalhado, juntamente com a equipe psicossocial da Seção Psicossocial Forense do Tribunal de Justiça do Distrito Federal e Territórios, numa perspectiva de avaliação e possível intervenção, sob o enfoque sistêmico (VASCONCELLOS, 2002), com o objetivo de auxiliar tanto o juiz em suas decisões, quanto a família em suas reflexões, buscando reconstruir a história familiar 
com novas narrativas e ampliando a compreensão de cada membro da família diante do contexto de sofrimento que afeta todos os seus membros. A contribuição da abordagem sistêmica deu-se no sentido de se compreender que o padrão de interação da família pode ser saudável, entendendo-se saudável como permeado por crises que, vistas como forma de crescimento, podem significar constantes transformações de cada um de seus membros (CALIL, 1987). Desta forma, o problema conjugal ou do casal deixa de ser visto na área da Justiça como sendo de dois indivíduos isoladamente, considerados como duas partes em litígio e em disputa. Nesse momento, o problema passa a ser visto como da unidade familiar, superando dessa maneira a causalidade linear para considerar o processo a partir da articulação do sujeito em todas as suas realidades: subjetiva, individual, social e cultural.

Assim, buscou-se aliar o pedido do juiz, que procura um embasamento técnico-pericial para a sua decisão legal, a um embasamento teórico-técnico que visasse: avaliar a dinâmica familiar, pensando na família como um todo; no assessoramento dos magistrados nas suas decisões; e intervir na dinâmica familiar, propiciando que a família retome o seu poder de decisão, ou seja, que a própria família encontre o consenso que priorize o bem-estar do grupo familiar.

Sendo assim, deixa-se de perceber o contexto da Justiça apenas em seus limites. Deixa-se também de argumentar apenas do ponto de vista jurídico, buscando superar a lógica do contraditório em relação à lógica do conciliatório, ultrapassando o olhar do juízo em direção a uma compreensão sistêmica relacional e contextualizada e de possibilidades de intervenções que propiciem mudanças, conforme discute Sudbrack (1998). Temos a acrescentar que a metodologia utilizada no trabalho tem sido revista periodicamente (CAMPOS; LIMA, 2003; COSTA; SANTOS, 2003; LIMA, 2003; RODRIGUES; LIMA, 2003; SANTOS; LIMA, 2003).

Temos a assinalar que a morosidade dos processos tem sido assunto na mídia em geral e tem preocupado os magistrados. Assim, cada vez mais os pedidos de estudo psicossocial chegam à Seção protocolados como urgente criando, com isso, uma demanda de atendimento rápido e com poucos contatos com a família. Santos B. S. et al. (1996), ao analisar a morosidade dos processos, aponta essa questão como uma importante interface entre o sistema judicial e o político. A "lentidão da justiça" não é um caso preocupante somente em nosso país. A demora no andamento dos processos não pode ser medida apenas do ponto de vista objetivo. Considerando a disputa de guarda, por exemplo, essa demora pode acirrar os ânimos das partes e, dessa forma, acabar criando mais debates e prolongamento no tempo para a busca de solução e acordos.

Verificamos que o processo traz o histórico da família, contada da forma como cada parte litigante vivenciou ou ainda está vivenciando a situação ali retratada. No caso dos processos referentes às Varas de Família, verificamos que o referido processo, embora dinâmico, é como se fosse o retrato tirado em um determinado tempo da história da família que, quando chega até nós, já mudou totalmente, mudou parcialmente ou está congelada nos relatos ali efetuados. E isso independe do tempo cronológico em que o processo foi formado. 
Shine (2003) aponta como uma das dificuldades do exercício do papel do profissional psicossocial o fato de que, de modo geral, o tribunal não está interessado na saúde mental das partes, mas sim nas condições e informações que promovam a "tomada de decisão". Porém, em um estudo recente, Ribeiro (2004) indica que a realização do estudo psicossocial de casos de abuso sexual envolvendo crianças depende da vinculação afetiva e emocional que esse profissional estabeleça com a criança, já que é ela que dá o sentido à execução do parecer.

Novamente nos vemos diante de situações diversas envolvendo o tempo que o magistrado necessita para dar uma sentença, o tempo que o profissional precisa para equacionar sua própria reação emocional diante do estudo e o tempo que a família leva para elaborar suas vivências. Assim, precisamos ter um tempo para conhecer a família, construindo uma relação que deve levar em conta o emocional de cada um de nós. Necessitamos de um tempo para fazer o movimento de pertencer e ser pertinente, como diz Andolfi (1981), com relação às vivências das famílias, ou às nossas; tempo para que possamos concluir a dupla tarefa de atendimento - pedido dos juízes x pedido das famílias -, fazendo as intervenções junto a essas últimas, que acreditamos serem importantes e necessárias, bem como conseguirmos dar as informações que os juízes esperam do nosso trabalho, para que nossas conclusões e sugestões possam fornecer o respaldo que os mesmos necessitam para fundamentar a decisão acrescentando a visão psicossocial.

\section{CONSIDERAÇões Finais}

Diante do que expusemos, como sair do dilema tempo-prazo estabelecido pelo juiz; tempo-prazo da família e cada um de seus membros, levando em conta as dimensões temporais sincrônica e diacrônica, tanto do profissional, quanto da família? O que fazer com o jogo familiar que diante de nós se apresenta, já que, muitas vezes, encontra-se aprisionado no seguinte paradoxo: quero mudar, mas não quero mudar?

Cada família necessita de um tempo para processar as intervenções por nós efetuadas durante a realização do estudo psicossocial, assim como necessita do tempo-decisão/judicial para definir/modificar a sua organização. Como conciliar o que está parecendo ser inconciliável, o tempo-prazo/duração do processo junto aos profissionais sendo que nem sempre é suficiente para realizar o tempo-prazo/ elaboração das ações técnicas para a finalização do estudo e fornecimento dos subsídios também suficientes para a decisão judicial? Como realizar esse desafio e procurar não viver constantemente a frustração na execução do trabalho?

Temos buscado algumas ações para amenizar tal dilema: redução do número de atendimentos para realização do relatório psicossocial; reavaliação do estudo na tentativa de captar possíveis significações posteriores ao mesmo; ampliação do conhecimento sobre o sistema social/comunitário em torno da família.

Não vemos essas ações como definitivas ou soluções perfeitas, mas esperamos estar contribuindo para o contexto decisório dos tribunais, ao problematizar o uso e a consideração do tempo para as diversas instâncias vinculadas aos processos judiciais. Finalizamos com uma poesia de Marcia Regina Ribeiro dos Santos: 
Há o TEMPO COMPOSTO do verbo amar: tenho amado; há também o TEMPO SIMPLES: amando.

No TEMPO DO REI VELHO, que é o mesmo de D. JOÃO CHARUTO e, igualmente, DO ONÇA e DO RONCA, esse vai longe.

Há também o TEMPO DA GERAÇÃO - em que tudo começou entre nós, entre vós e entre eles, necessitando de um TEMPO DE ACESSO e DE ENTRADA entre e com cada um.

Há um TEMPO em que as VACAS estão GORDAS e também outro em que as VACAS estão MAGRAS. Além disso, há o TEMPO DE PROJEÇÃO entre mim e ti.

Conhecemos o TEMPO DE RELAXAÇÃO, DE RESIDÊNCIA E DE RESOLUÇÃO utilizando TEMPO INTEGRAL com cada um.

Existe o TEMPO que está MORTO, esse já foi.

Existe o TEMPO PRÓPRIO, esse é de cada um.

Há o TEMPO SIDERAL e o TEMPO UNIVERSAL já que os astros, assim como nós, fazem parte do universo.

Entretanto, tudo acontece A TEMPO e A HORA e, às vezes, A UM TEMPO SÓ ou A UM SÓ TEMPO ou, até mesmo, EM DOIS TEMPOS, conosco e junto às famílias que atendemos.

Muitas vezes, ou de TEMPOS EM TEMPOS, damos TEMPO AO TEMPO ou atuamos em TEMPO RECORDE.

Às vezes a família vem com o TEMPO FECHADO, não dando espaço ou, até mesmo, todos FECHAM O TEMPO, ou ainda, mantêm o TEMPO QUENTE por muito TEMPO.

Mas, mesmo assim, tentamos GANHAR TEMPO ou MEIO TEMPO, MATANDO-O ou NÃO TENDO TEMPO NEM PARA NOS COÇAR.

No final das contas, passamos uma boa TEMPORADA PERDENDO, mas sem dúvida também GANHANDO TEMPO com todas as famílias que passam pela Seção Psicossocial Forense do Tribunal de Justiça do Distrito Federal e Territórios.

\section{REFERÊNCIAS}

BRASIL. Tribunal de Justiça do Distrito Federal e Territórios. A nova justiça: tendências e desafios. Brasília, DF, 2006.

ANDOLFI, M. A terapia familiar. Lisboa: Vega, 1981.

; ÂNGELO, C. Tempo e mito em psicoterapia familiar. Porto Alegre: Artes Médicas, 1989.

ARAÚJO PINTO, C. P. Modernidade, tempo e direito. Belo Horizonte: Del Rey, 2002. 
Marcia Regina Ribeiro dos Santos e Liana Fortunato Costa

BERGÉ, P.; POMEAU, Y.; DUBOIS-GANGE, M. Dos ritmos ao caos. São Paulo: UNESP, 1996.

BOSCOLO, L.; BERTRANDO, P. Los tiempos del tiempo: una nueva perspectiva para la consulta y la terapia sistêmicas. Barcelona: Paidós, 1996.

BOSZORMENYI-NAGY, I.; SPARK, G. Lealtades invisibles. Buenos Aires: Amorrortu, 1983.

CALIL, V. L. Terapia familiar e de casal. São Paulo: Summus, 1987.

CAMPOS, N. M. V.; LIMA, H. G. D. Abuso sexual intrafamiliar: um estudo de caso e a perspectiva de uma intervenção em rede. In: LIMA, H. G. D. (Org.). Construindo caminhos para a intervenção psicossocial no contexto da justiça. Brasília, DF: TJDFT, 2003. p. 143-155.

COSTA, L. F.; SANTOS, V. A. Em nome do pai: um romance familiar construído com a participação da Justiça. Mudanças - Psicologia da Saúde, São Paulo, v. 12, n. 1, p. 167-191, jan./jun. 2004a.

. Família e violência sexual contra crianças: o papel da justiça na construção e reconstrução de significados. Psicologia: Teoria, investigação e prática, Minho, v. 9, n. 1, p. 47-63, fev. 2004b.

. Violência sexual: um fenômeno multifacetado que lança o desafio de um trabalho interdisciplinar no contexto judiciário. In: LIMA, H. G. D. (Org.). Construindo caminhos para a intervenção psicossocial no contexto da justiça. Brasília, DF: TJDFT, 2003. p. 208-217.

COSTA, L. F.; PENSO, M. A.; ALMEIDA, T. M. C. O Grupo Multifamiliar como um método de intervenção em situações de abuso sexual infantil. Psicologia USP, São Paulo, v. 16, n. 4, p. 121-146, 2005.

DELMAS-MARTY, M. Acesso à humanidade em termos jurídicos. In: MORIN, E. (Org.). A religação dos saberes: o desafio do século XXI. Rio de Janeiro: Bertrand Brasil, 2001. p. 257-266.

GRANDESSO, M. A. Sobre a reconstrução do significado: uma análise epistemológica e hermenêutica da prática clínica. São Paulo: Casa do Psicólogo, 2000.

. Terapias posmodernas: un panorama. Sistemas Familiares, Buenos Aires, v. 18, n. 3, p. 19-27, 2002.

LIMA, H. G. D. (Org.). Grupos Multifamiliares como uma possibilidade de intervenção na justiça. In: Construindo caminhos para a intervenção psicossocial no contexto da justiça. Brasília, DF: TJDFT, 2003. p. 106-123.

OLIVEIRA, E. Da visão jurídica. In: CEZAR-FERREIRA, V. A. da M. Família, separação e mediação: uma visão psicojurídica. São Paulo: Método, 2004. p. 1116 (prefácio). 
PAPERO, D. V. A teoria sobre os Sistemas Familiares de Bowen. In: ELKAÏM, M. (Org.). Panorama das terapias familiares. São Paulo: Summus, 1998. p. 71-100.

PAULO, V.; ALEXANDRINO, M. Direitos fundamentais. Niterói: Impetus, 2002. PESSIS-PASTERNAK, G. Ilya Prigogine, arquiteto das "estruturas dissipativas". In: . (Org.). Do caos à inteligência artificial: quando os cientistas se interrogam. São Paulo: UNESP, 1993. p. 35-49.

PROJETO Justiça Comunitária. Projeto apresentado ao Tribunal de Justiça do Distrito Federal e Territórios. Brasília, DF, 2001.

RIBEIRO, R. As emoções do profissional psicossocial com o abuso sexual. 2004. Dissertação (Mestrado)-Universidade de Brasília, Brasília, DF, 2004.

ROMÃO, J. E. E. A Mediação como Procedimento de Realização da Justiça no Âmbito do Estado de Direito. Revista dos Juizados Especiais do TJDFT, Brasília, DF, p. 25-49, jul./dez. 2001.

RODRIGUES, D. M.; LIMA, H. G. D. Intervenções sistêmicas em um contexto de decisão. In: LIMA, H. G. D. (Org.). Construindo caminhos para a intervenção psicossocial no contexto da justiça. Brasília, DF: TJDFT, 2003. p. 21-44.

SANTOS, B. S. Pela mão de Alice: o social e o político na pós-modernidade. 2. ed. São Paulo: Cortez, 1996.

SANTOS, B. S. et al. Os tribunais nas sociedades contemporâneas. Porto: Afrontamento, 1996.

SANTOS, J. A. C.; LIMA, H. G. D. O ritual e a justiça na construção de um caminho de ajuda. In: LIMA, H. G. D. (Org.). Construindo caminhos para a intervenção psicossocial no contexto da justiça. Brasília, DF: TJDFT, 2003. p. 157-178.

SCHNITMAN, D. F. Novos paradigmas na resolução de conflitos. In: SCHNITMAN, D. F.; LITTLEJOHN, S. (Org.). Novos paradigmas em mediação. Porto Alegre: Artes Médicas, 1999. p. 17-27.

SHINE, S. A espada de Salomão: a psicologia e a disputa de guarda dos filhos. São Paulo: Casa do Psicólogo, 2003.

SUDBRACK, M. F. O. Psicólogos no contexto da justiça: agentes de controle ou de mudança? Texto didático do curso de extensão universitária: abordagem da família no contexto judicial. Universidade de Brasília, Brasília, DF, 1998.

TUCCI, J. R. C. Tempo e processo. São Paulo: Revista dos Tribunais, 1997.

VASCONCELLOS, M. J. E. Terapia familiar sistêmica: bases cibernéticas. São Paulo: Psy, 1995.

. Los nuevos conceptos-1lave em terapia familiar. Sistemas familiares, Buenos Aires, v. 12, n. 2, p. 53-58, 1996. 
Marcia Regina Ribeiro dos Santos e Liana Fortunato Costa

VASCONCELLOS, M. J. E. Pensamento sistêmico: o novo paradigma da ciência. São Paulo: Papirus; Porto Alegre, UFMG, 2002.

Recebido em: fevereiro/2006

Aceito em: junho/2006 